ve a considerar que, a pesar de la estimación global de Sigüenza, es probable que el destruido San Juan en Patmos de El Escorial no fuera obra que supusiera «tanta mudanza» con relación a las cuatro pinturas de la sacristía de prestado y que en realidad su creación tuviera lugar por 1572 y antecediera a la de la Adoración de los Pastores y la Sagrada Familia con San Joaquín y Santa Ana, aproximándose en lo estilístico al San Jerónimo y al Martirio de Santiago, como ocurre en este lienzo del museo diocesano, que bien pudo preceder a la versión definitiva ${ }^{39}$ y en el que ni se aprecia la intervención de dos manos ni hay nada de la última manera de Navarrete, lo cual excluye que sea una de las pinturas inconclusas entregadas a García de Brizuela. Así, la sensación de una fragilidad y estilización figurativa y de un sentido de las texturas ajenos al hacer de El Mudo encuentra un adecuado engarce en su evolución estilística, fuera ya de la excesiva definición dibujada de las formas aún patente por 1571 y antes de los desleimientos pictóricos de su obra madura ${ }^{40}$, y se verifica con una complacencia en mostrar la suavidad de la incipiente barba del joven apóstol y la riqueza de los matices cutáneos faciales denotadoras de un elevado grado de maestría técnica; y si bien el escorzo de la hermosa cabeza del santo difiere del más sólido y «correcto» de Santiago en la pintura de su martirio - como éste del de algún otro-, no puede dejar de notarse, abundando en lo ya estimado, una singular proximidad en aspectos como el tratamiento del cabello o el modo en que están pintadas las ojeras y algún pequeño pliegue facial, y la misma forma nasal, delgada y algo puntiaguda, es versión escorzada de la habitual en sus modelo figurativos más delicados. Habra así que concluir que se trata de una primera o quizá segunda versión del San Juan en Patmos de El Escorial, de la que no queda memoria, y que corresponde a un momento de transición estilística en la producción temprana de Navarrete en los inicios de su trayectoria escurialense.

Fernando Collar de CÁceres Universidad Autónoma de Madrid

\title{
FLORES, FERNÁNDEZ Y OLIVA: TRES AZULEJEROS PARA LAS OBRAS REALES DE FELIPE II
}

Que las obras de arquitectura promocionadas por Felipe II eran acabadas frecuentemente con revestimientos de azulejos es una idea conocida desde hace tiempo. El ejemplo más frecuentemente aducido es el de los aposentos del mismo rey en el Monasterio de San Lorenzo de El Escorial aunque podrían ser citados muchos más casos conservados y otros conocidos a través de la documentación. Este rasgo de la arquitectura filipina y el personal interés del rey por el asunto debió ser un importante acicate para el desarrollo de la azulejería española en la segunda mitad del siglo XVI ${ }^{1}$.

\footnotetext{
${ }^{39}$ En tal sentido se refiere a la Flagelación de Cristo después de hablar de la Adoración de lo Pastores y de la Sagrada Familia con San Joaquín y Santa Ana, aparte de lo relativo a la pintura de San Juan. El criterio es del todo claro cuando habla de las pinturas de la sacristía de Prestado, que comienza con la «muy acabada» pintura de la Asunción de la Virgen, para seguir con la del martirio de San Felipe, «algo desgraciado por el colorido de las ropas», y pasar luego a San Jerónimo penitente y al Martirio de Santiago.

${ }^{40}$ Ambos extremos concurren en el Martirio de Santiago, de 1571, manteniendo en buena manera las figuras principales la solidez dibujada de su San Jerónimo penitente e inaugurando el paisaje, con sus figuras casi inmateriales, la factura cromática y abocetada de su producción posterior, bien patente en lo lejos de las parejas de apóstoles y en algunas figuras de singular concepto veneciano, como el ángel de San Mateo.

' Sobre este período talaverano pueden consultarse: Vaca y González, Diodoro y Ruiz de Luna, Juan: La cerámica de Talavera de la Reina y algunos datos sobre la de Puente del Arzobispo. Madrid, 1943; Alice Wilson
} 
Tres artistas han sido citados desde hace años como autores de los azulejos para Felipe II. Por un lado, el flamenco Juan Flores, del que tan sólo se tenían unas pocas noticias literarias sobre su vida y su obra y que recientemente he tenido la oportunidad de revisar a luz de nuevos documentos y obras ${ }^{2}$. Otro azulejero es Juan Fernández, figura sobre la que aún se ciernen muchas dudas, con una biografía difusa y un catálogo de atribuciones muy engrosado. El tercero, José de la Oliva, es conocido, sobre todo, por ser autor de dos extraordinarias obras firmadas por él: el zócalo de la Sala del Consejo de la Generalitat de Valencia y el pavimento de la capilla del palacio de la Cerda, hoy Convento del Carmen Descalzo, en Toledo ${ }^{3}$. Más recientemente, Ray en un trabajo muy clarificador, apoyado en documentación publicada por Gregorio de Andrés, ha llamado la atención sobre la obra de Fernández y de Oliva como productores de azulejos para el rey, concretamente para El Escorial ${ }^{4}$. En las líneas que siguen se darán algunos datos inéditos más sobre la obra cortesana de los dos últimos azulejeros citados.

Por otro lado, estas tres figuras importantes se conocían de forma independiente ya que hasta ahora los posibles lazos entre ellas no sobrepasaban el nivel de la pura sospecha para algunos investigadores. Más adelante comprobaremos que algunos de estos lazos entre Fernández y Oliva, hasta ahora supuestos, eran reales.

La documentación inédita hallada sobre dos episodios concretos, nos da la oportunidad de introducirnos en esta trama: el primero de ellos es el relevo probable de Fernández en el cargo como proveedor oficial de azulejos del rey tras la muerte de Flores en 1567. El segundo, los celos profesionales que Oliva suscita en Fernández a propósito de la competencia que aquél le hace en los encargos reales.

Con respecto al primero de ellos, sabemos que Flores había suministrado los azulejos de pavimentos y zócalos para los Aposentos del Rey y las Caballerizas con su Armería en el Alcázar de Madrid. Después de terminadas estas partes, ya fallecido Flores, era la Torre Nueva o Torre Dorada II el siguiente conjunto necesitado de revestimientos (Fig. 1). En ese contexto, Andrés de Ribera, proveedor de materiales para la obra, escribe al secretario del Consejo de Su Magestad, Martín de Gaztelu, dos cartas que poseen para nosotros un enorme interés. En la primera de ellas, datada el 1 de junio de 1569, dice que un nuevo oficial — del que no cita nombre - ha ofrecido sus servicios para hacer los chapados que se necesitan para la Torre Nueva ${ }^{5}$. Comenta Ribera que los azulejos del aspirante, de hermosos colores, no sólo son mejores que los de Flores sino, además, más baratos. También informa que ya le ha comprado una partida de ellos para el aposento del Rey en el monasterio de San Jerónimo de Madrid (Fig. 2) ${ }^{6}$.

Frothingham: Tile panels of Spain. New York, 1969; Martínez Caviró, Balbina: «Azulejos talaveranos del siglo xvI». Archivo Español de Arte, 1971, $\mathrm{n}^{\circ}$ 173-176, pp. 283-293; Ray, Anthony: «Sixteenth century pottery in Castile: a documentary study». Burlington Magazine, n. ${ }^{\circ}$ 1058, mayo 1991, pp. 298-305 y finalmente, Pleguezuelo, Alfonso: «Retazos de una historia» en Cat. Exp. Talaveras de la Colección Carranza. Talavera, 1994, pp. $17-45$.

${ }^{2}$ Nuestro trabajo sobre Floris fue presentado por primera vez en el marco de la Conferencia A splendid isolation? Spanish Cultural identity and the Visual arts 1500-1700, con el título «Hans Floris, Supplier of Glazed Tiles to Philip II». El tema fue revisado en la I Antwerp Conference on majolica and glass (Amberes, 1999) y el trabajo será publicado en las Actas de esta última reunión con el título «Jan Floris (c. 1520-1567) a Flemish tile maker in Spain» Brabom (Amberes, 2000) (en prensa). Sobre el mismo artista puede leerse nuestro artículo «Los azulejos del pavimento de la capilla de los Benavente en Medina de Rioseco. Una posible obra de Juan Flores». Boletín del Seminario de estudios de Arte y Arqueología. Universidad de Valladolid, 1998, pp. 291-306.

${ }^{3}$ Para la obra de azulejos de la Generalitat de Valencia véase Soler, María Paz: Historia de la cerámica valenciana. Vol. III, Valencia, 1989, pp. 22-25. La obra del palacio de la Cerda de Toledo ha sido dada a conocer y reproducida por Martínez Caviró, Balbina: Conventos de Toledo. Eds. El Viso, Madrid, 1990, p. 349.

${ }_{4}$ El trabajo de Ray (ob. cit. pp. 301 y 302) es el único que hasta ahora ha hecho hincapié en esta faceta cortesana del azulejero Juan Fernández.

5 Archivo General de Simancas, Casa y Sitios Reales, leg. 247-1, fol. 185 (Doc. 1).

${ }^{6}$ Sabemos por documentación que un tal Lorenzo de Segovia, de Toledo, suministró azulejos para este sitio real $\mathrm{y}$, aunque sospechamos que este artesano enviaba azulejos de arista, es probable que también Juan Flores hubiera 

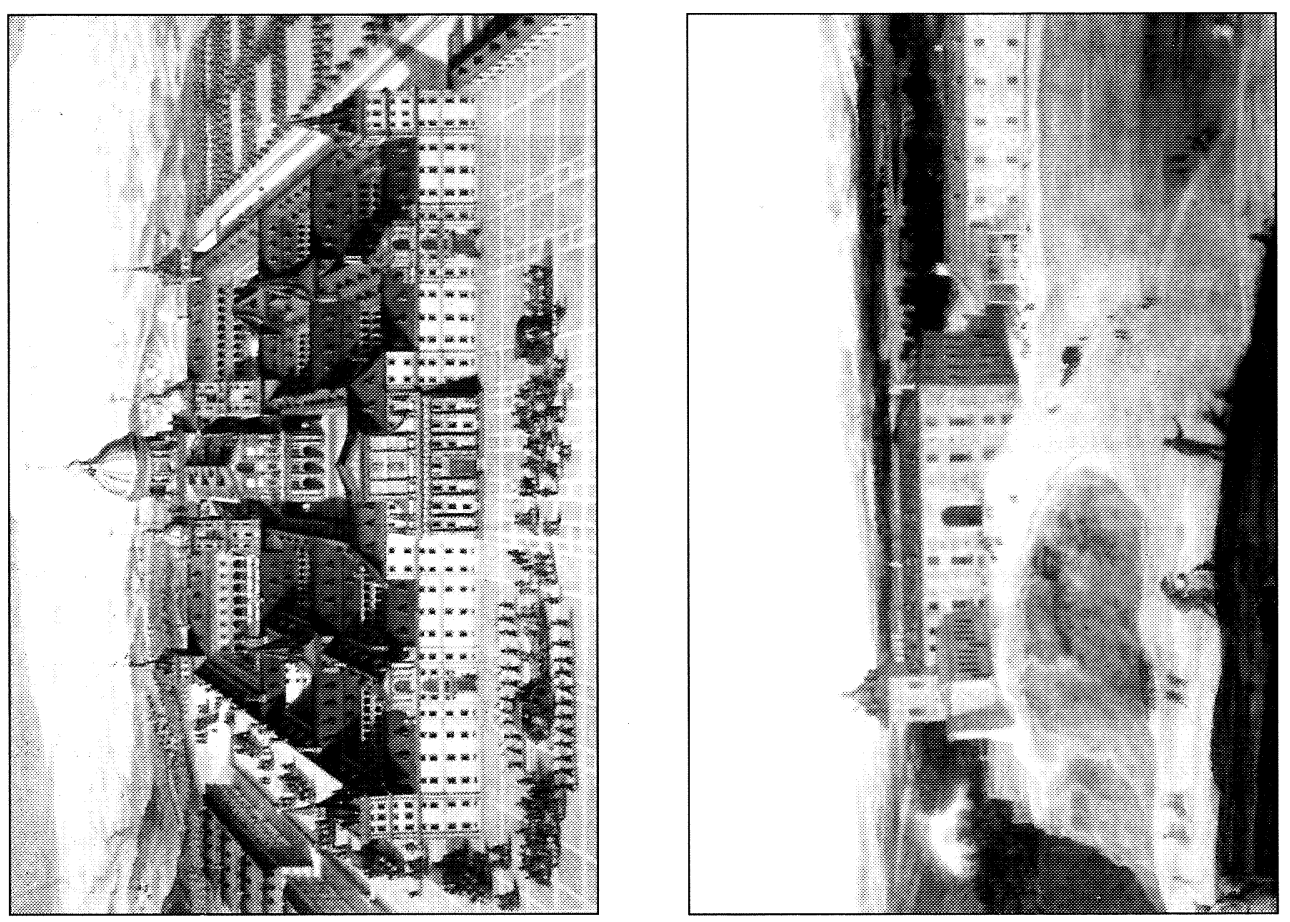

昜

.

它画

承

造

要的

응 解

Z

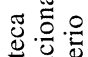

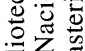

용

के $\overline{2}$

票 $\dot{0}$

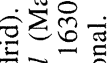

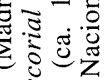

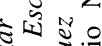

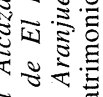
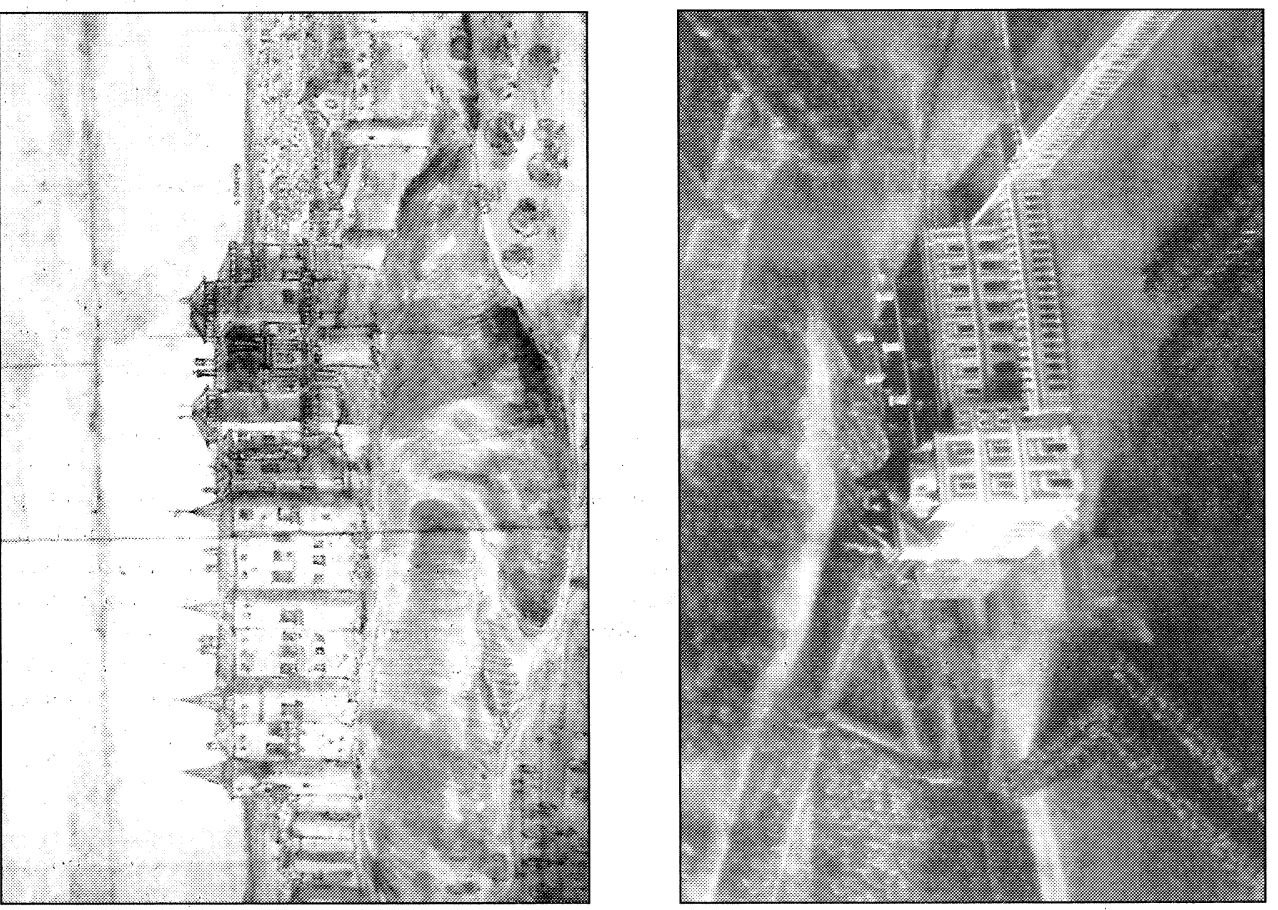

$\widetilde{3}:$

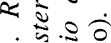

它政券

ฮู छัّ

a

远

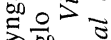

उक

可语歌

雪

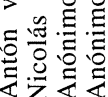

-

on on bo bo bo

AEA, LXXV, 2002, 298, pp. 191 a 216 
Algunos días más tarde, informa nuevamente al secretario de que ha realizado ya con el competente ceramista un acuerdo previo al nombramiento oficial como proveedor de las obras del rey, fijando en él los precios de sus productos. También comenta que le había devuelto las muestras que presentó para que las viera $\mathrm{Su}$ Magestad ya que había expresado un interés especial en ello ${ }^{7}$.

El rey debió dar su aprobación a tales muestras y el nuevo proveedor suministraría finalmente sus azulejos policromos pintados para la Torre Dorada y poco después comenzaría a fabricarlos para el Escorial ${ }^{8}$. Sabemos que el 29 de enero de 1570 Juan Fernández firma su primer contrato para el gran monasterio ${ }^{9}$ y que trabajó para el rey desde la fecha antes indicada hasta $1578{ }^{10}$. Es decir, igual que Flores había sido el proveedor de azulejos del rey entre 1562 y 1567 , Fernández le sucedió en el cargo haciendo su papel durante casi toda la década de los setenta.

Pasan los años y cuando aún trabajaba Juan Fernández para el rey, en

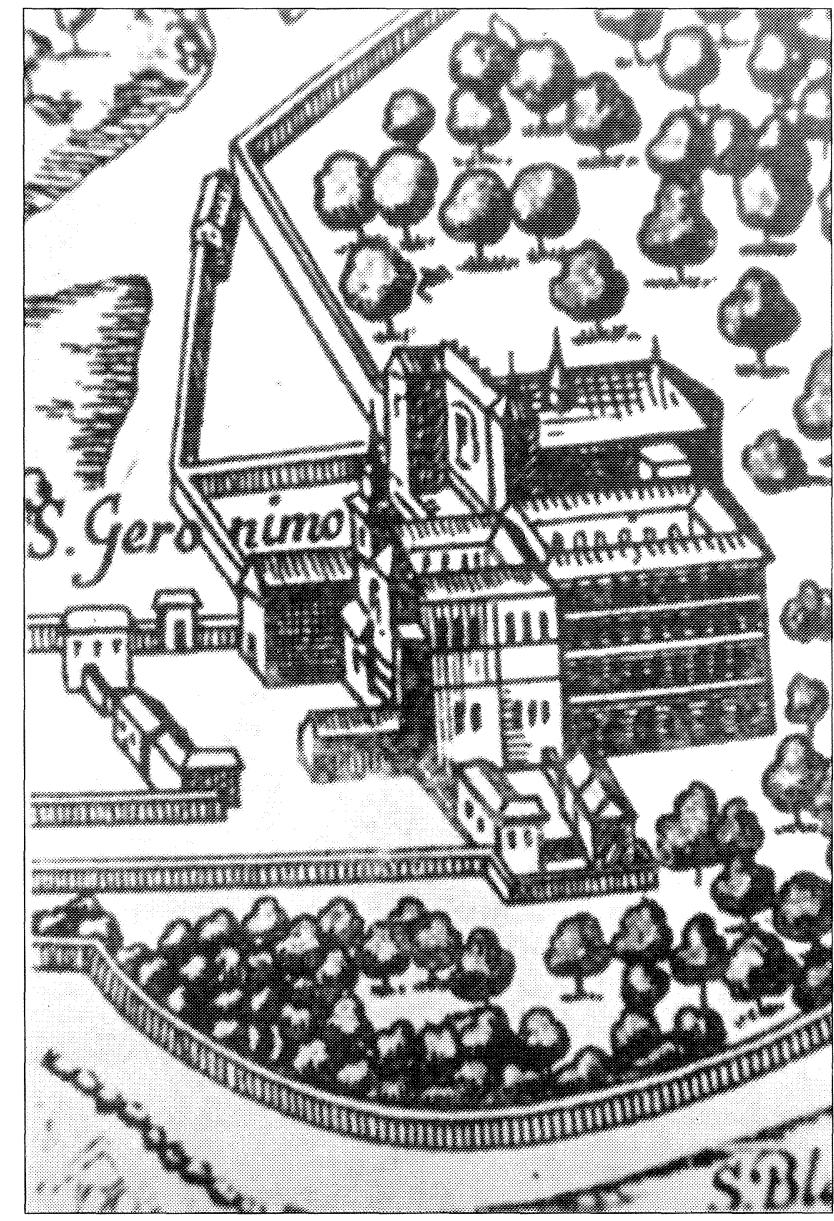

Fig. 2. De Wit. Plano de Madrid. Siglo xviI. Detalle del Real Monasterio de San Jerónimo 13 de mayo de 1577 , Oliva, siendo vecino de Toledo, firma un contrato de suministro de azulejos para El Escorial (Fig 3) ${ }^{11}$. Imaginamos que esta operación no debió ser vista con buenos ojos por Juan Fernández, de manera que, en el momento en que encontró la excusa algún tiempo después, expresó su malestar.

En efecto, al año siguiente, Oliva recibe un pago por la labor contratada aunque también trabajaban entonces para el monasterio Gabriel García, azulejero de Toledo, como él, y dos maestros más de Talavera: Juan Fernández y Francisco Hernández. Al parecer, Oliva no fue citado más en los documentos relacionados con El Escorial, lo que hace pensar lógicamente en su posible fallecimiento hacia $1578{ }^{12}$.

remitido desde Talavera azulejos pintados a la manera renacentista. En este sentido, a su muerte, resultaría lógico que algún otro azulejero que dominara la misma técnica se encargara de proveer este tipo de materiales que irían combinados con los azulejos de arista y los ladrillos toledanos, como en otros conjuntos cortesanos.

7 Archivo General de Simancas, Casa y Sitios Reales, leg. 247-1, fol. 185 (Doc. 2).

${ }^{8}$ Es de suponer que el nombramiento de proveedor de azulejos del rey se produciría aunque no hay constancia documental de ello a diferencia del caso de Juan Flores.

9 Vaca y Ruiz de Luna: op. cit., pp. 176-178.

${ }^{10}$ Algunas precisiones sobre la obra de este artista pueden ser halladas en Ray: ob. cit., pp. 299-300.

$"$ Andrés, Gregorio de: Inventario de documentos sobre la construcción y ornato del Monasterio del Escorial existentes en al archivo de su Real Biblioteca. Anejo de Archivo Español de Arte, (1972-75), n. ${ }^{\circ}$ 177, 181, 183, $185,189,190,192$ y 194

12 Ray: ob. cit., p. 302. 
Pero si así fue, debió ser después del mes de octubre ya que antes había tenido lugar un episodio relacionado con algunas construcciones reales y del que son protagonistas los dos azulejeros que nos ocupan.

Los hechos están relacionados con los chapados de cerámica que se proyectan para el Palacio de Aranjuez (Fig. 4). A propósito de ello, se produce una disputa profesional bajo la que se adivinan tensiones y competencias más antiguas. Fernández, ante el ascenso progresivo de Oliva, debió ver amenazada su posición como proveedor oficial y presentó quejas al rey con una carta cargada de rabia mal disimulada y cuyo contenido conocemos por el informe que de ella hace un funcionario el 15 de octubre de $1578{ }^{13}$. Según el secretario, Juan Fernández, que llevaba sirviendo al rey en su oficio durante diez años, protesta porque la obra de los azulejos del palacio de Aranjuez se la quieren dar a «un oficial que trabaxaba con éll en su casa» ${ }^{14}$. Fernández, además, se permite decir que los azulejos que se han colocado en la Casa de Açeca, que Oliva ha vendido a 15 maravedis y medio la pieza, él la hubiera hecho cobrando sólo un quartillo por cada una (Fig. 5) ${ }^{15}$. Argumenta que él puede hecerlo así porque: «tiene entendidos todos los secretos deste oficio y tiene todos los aparexos en su casa» mientras que «todo esto le falta a quien agora se le quieren dar (sic) la dicha obra y se a de ayudar de otras personas que no entenderán como el» ${ }^{16}$.

Por petición del secretario, el gobernador del palacio de Aranjuez, Alonso de Mesa, presenta el día 18 del mismo mes y año, un informe dando su versión de los hechos ${ }^{17}$. En él comenta que Fernández había dado azulejos para el Escorial y para Aranjuez y que ahora pretendía recibir el encargo de los que se harían para el Quarto Real de este último palacio. Dice también que Juan de Herrera había encargado a Oliva hacer «muestras y designios» para esta obra y que pretendía que la ejecutaran entre él y Fernández para mayor rapidez ${ }^{18}$. A esta propuesta oficial de colaboración, Oliva objeta que tiene ya un compromiso adquirido con otros oficiales de Toledo ${ }^{19}$. Fernández, a decir del funcionario consultado, se limita a retirar-

\footnotetext{
13 Archivo General de Simancas, Casa y Sitios Reales, leg. 247-1, fol. 235 (Doc. 3).

14 Esta frase que consideramos clave para la desconocida filiación artística de Oliva puede interpretarse como mínimo de dos formas: o bien, el jóven artista había sido aprendiz y oficial con él o, bien, había sido simplemente oficial a su servicio aunque pudiera haberse formado como aprendiz fuera del mismo, por ejemplo, con el propio Juan Flores recién fallecido. Aunque esta segunda fórmula no era extraña en la fecha, vemos probable que Oliva aprendiera el oficio de ceramista con Fernández. Al fin y al cabo, no había tantos talleres en esos años que dominasen esta técnica de la pintura policroma y el de Fernández debía ser uno de los mejores después de la muerte de Flores.

15 Açeca era un caserío de unos pocos de edificios en el camino entre Aranjuez y Toledo. En esta aldea, tenía el rey una casa de parada y pabellón de caza que se renueva por orden de Felipe II. Por un plano conservado en Simancas sabemos que era una construcción casi cuadrada con patio central, pilares y cuatro cuartos más cocinas (Archivo General de Simancas, Casa y Sitios Reales, leg. 248, fol. 66). Actúan en Aceca varios arquitectos de forma sucesiva con obras que se dilatan de forma indefinida. En 1558 estaban terminados tres de los cuatro cuartos y pendientes de colocación los pilares del patio. En 1569 se hacen visitas a la obra (Archivo General de Simancas, Casa y Sitios Reales, leg. 252/4, fol. 264) y antes de 1578 están instalados ya los chapados de azulejo. Conocemos del aspecto exterior de este sitio real por la reproducción que de él hace un cuadro atribuido a Juseope Leonardo, conservado en El Escorial y que muestra una vista del mismo. Véase Wilkinson, Catherine: Juan de Herrera. Architect to Philip II of Spain. Yale University Press. Yale, 1993, fig. 62. También se reproduce esta pintura en el Cat. Exp. Felipe II. El Rey íntimo. Jardín y Naturaleza en el siglo xvi. Aranjuez, 1998. Fig. 150. Para la historia documental del edificio véase Rivera, Javier: Juan Bautista de Toledo y Felipe II. La implantación del clasicismo en España. Valladolid, 1984. pp. 183-192.

${ }^{16}$ Como puede apreciarse por el tono del comentario, Fernández no niega la profesionalidad de Oliva sino que sólo pone en tela de juicio la de sus ayudantes.

17 Archivo General de Simancas, Casa y Sitios Reales. leg. 247-1, fol. 235 vto. (Doc. 4)

18 No sabemos cómo interpretar exactamente las palabras «muestras y designios». El primero de los términos es posible que se refiera a azulejos propiamente dichos realizados como prototipos con los colores definitivos. El segundo de ellos debe referirse a los dibujos de los motivos hechos probablemente sobre papel.

${ }^{19}$ No sabemos si las excusas de Oliva son sinceras o si se trata sólo de una estrategia para hacerse con el encargo de forma exclusiva. Tampoco sabemos si era una revancha por diputas anteriores con Fernández.
}

AEA, LXXV, 2002, 298, pp. 191 a 216 
se no sin antes presentar una oferta en que rebajaba el precio de la obra nada menos que en 500 ducados ${ }^{20}$. Ambos artistas, al parecer, escriben a Juan de Herrera exponiendo sus argumentos y en la fecha de la carta, aún no se ha tomado una decisión al respecto.

Tan espinoso asunto podría tener, entre otras posibles, la siguiente explicación: Oliva - que tal vez no fuese aún maestro examinado-, después de trabajar como oficial con Fernández en Talavera, se independizó trasladándose a Toledo donde, al carecer de taller propio, formó compañía con otros oficiales que pusieron el suyo a disposición de la nueva empresa ${ }^{21}$. Esto debió producirse antes de 1575 , fecha de la que data el pavimento del palacio de la Cerda, firmado ya por Oliva en Toledo, igual que el magnífico zócalo para el Salón del Consejo de la Generalitat de Valencia. Oliva debe contratar por estas fechas los azulejos de la Casa Real de Açeca y poco después los de El Escorial, al tiempo que hace gestiones para conseguir también la exclusiva de los del Quarto Real del palacio de Aranjuez para el que, como hemos comprobado, ha suministrado diseños propios a petición de Juan de Herrera. La elección de Herrera en favor de Oliva para un paso tan importante como suministrar «las muestras y designios», y la convocatoria de Fernandez sólo para el pedido se haga con mayor rapidez dejan imaginar qué nivel de valoración sentía el arquitecto del rey por el trabajo de ambos artistas.

Fernández debió sentirse desplazado por la nueva empresa toledana e interpretar la actitud de Oliva como «competencia desleal» de un antiguo discípulo o, como mínimo, colaborador suyo. Aunque, como he apuntado más arriba, es posible que Oliva hubiera aprendido con Fernández la técnica de la cerámica, no vemos probable, desde luego, que pudiera aprender de él el oficio de pintor ya que en ese aspecto era muy superior al supuesto maestro ${ }^{22}$. La calidad de su obra hace pensar que, al igual que Flores, Oliva fuese pintor además de ceramista. Sólo así se justificaría la calidad pictórica de su obra conocida y el hecho de que Juan de Herrera lo designara a él y no a Fernández para hacer los diseños de los nuevos patrones para Aranjuez. No sabemos si el oficio de pintor, pudo incluso haberlo aprendido con Flores como otros lo habían hecho en Plasencia ${ }^{23}$.

El problema de fondo parecía residir en que Oliva era un artista excepcional y Fernández, un maestro que se resistiría a admitir la superioridad de su antiguo colaborador. Flores y Oliva, cada uno en su estilo, son, sin duda alguna, los dos mejores pintores de azulejos de la península ibérica en la segunda mitad del siglo xvi. Era previsible que antes o después Oliva, una vez fallecido Flores, suplantara al que había sido su superior, máxime cuando éste, aunque demuestra con sus obras ser un excelente técnico, debió haber sido siempre, como artista, más mediocre que el brillante discípulo.

No hemos podido aún averiguar el final de este episodio pero todo parece indicar, en

\footnotetext{
20 No conocemos el monto total del pedido pero, en cualquier caso, considerando que el precio medio por azulejo era entre doce maravedis y un real, una rebaja de 500 ducados es una cifra extraordinaria que nos permite pensar que el revestimiento proyectado era una obra de enorme empeño artístico y que la oferta de Fernández dejaba clara una voluntad desmedida en que el encargo no se le escapara de las manos. Probablemente supondría que si perdía éste, perdería todos los demás en adelante, como así fue, en efecto.

21 Estos oficiales, cuyos nombres desconocemos, deben ser aquellos con los que, comenta Oliva, se siente comprometido para fabricar los azulejos del Cuarto Real de Aranjuez. Curiosamente esta idea que ahora sabemos por documentación fue dada por Artiñano («Los orígenes de Talavera. Las imitaciones». Colecionismo 1920) sin especificar la fuente.

${ }^{22}$ Esta idea no deja de ser por el momento una mera hipótesis dado que la obra de Fernández, a pesar de estar muy documentada, no ha sido aún plenamente identificada.

${ }^{23}$ Se conocen por documentación dos aprendices de Juan Flores durante la etapa en que el artista se establece en Plasencia. Véase Martínez Quesada, J.: «Notas documentales sobre el Divino Morales y otros artistas y artesanos de Extremadura», Revista de Estudios Extremeños, Tomo XVII, 1961, p. '94. No sabemos si esta doble actividad como pintor de caballete y como pintor de cerámica que Flores practicó en su fase placentina fue también continuada en la fase talaverana.
} 
efecto, que Oliva fallece y que Fernández desaparece de esta escena. Lo cierto es que hacia 1580, un nuevo maestro de azulejos de Toledo, Juan de Vera, comienza a cubrir una parte sustancial de los encargos de las obras del rey y que lo hará durante los siguientes quince años ${ }^{24}$

Hasta ahora sabíamos que Fernández había suministrado azulejos para el Escorial. Ahora también sabemos que los fabricó para algunas partes del Palacio Real de Aranjuez y podemos atribuirle los de la Torre Dorada II y los del aposento del rey en el Monasterio de San Jerónimo ${ }^{25}$.

Por otra parte, sabíamos también que Oliva había firmado los del palacio de la Cerda en Toledo, los de la Generalitat de Valencia y que había contratado algunos para el Escorial. Ahora podemos añadir a su catálogo los de la Casa Real de Açeca y los diseños y muestras para los azulejos del Cuarto Real de Aranjuez que no sabemos si finalmente llegó a realizar.

Otro de los asuntos que hasta el momento era completamente desconocido y sobre el que los especialistas se habían pronunciado en sentidos muy dispares era la formación de José de la Oliva. Una fase toledana era evidente desde el momento en que se conoció la firma de su obra para Valencia pero la incógnita la constituía su etapa previa. Artiñano, no sabemos si apoyado de nuevo en su intuición o en documentos que no cita, vincula a Oliva con Juan Fernández en Talavera durante una primera etapa ${ }^{26}$. Autores posteriores han puesto en duda esta posibilidad sugiriendo una formación en Amberes en el taller de Guido Andríes ${ }^{27}$ o en Sevilla, en el de su hijo Frans Andríes ${ }^{28}$. Sin eliminar estas posibilidades y acudiendo sólo a los documentos aquí dados a conocer, la hipótesis que parece más plausible es la inicial de Artiñano. Al menos, hay ya alguna razón para suponer una relación de dependencia respecto de Juan Fernández en Talavera como oficial suyo aunque en ningún momento se comente si fue también su aprendiz ${ }^{29}$. Nos inclinamos a pensar que Oliva tuvo contacto directo con Flores antes de 1567. Ello explicaría la calidad de su obra y su carácter marcadamente flamenco y, tal vez, su rivalidad con Fernández, otro posible condiscípulo de Flores en el terreno cerámico.

En cualquiera de los casos, se confirma en parte que la línea de trasmisión del repertorio ornamental y de la tecnología debe ser la que hasta ahora se había supuesto sin base documental. De Flores a Fernández y de éste a Oliva aunque hay otros ceramistas importantes y aún por conocer mejor como Figueroa, Díaz o Loaysa que trabajaban en la misma y aún nebulosa órbita.

\section{Documento n.0 1}

1 - junio - 1569

Carta de Andrés de Ribera a Martín de Gaztelu, Secretario del Consejo de su majestad, sobre el nuevo azulejero que ha ofrecido sus servicios.

Archivo General de Simancas. Casa y Sitios Reales. Leg. 247-1, Fol. 183.

«aquy a benydo un muy buen official de azulejos de muy lyndas colores $\mathrm{p}^{\mathrm{a}}$ hazer lo necesaryo $\mathrm{p}^{\mathrm{a}}$ la torre nueba - a me pedydo a catorze maravedys por cada uno entyendo que los hara a doze maravedys. Son mejores

\footnotetext{
${ }^{24}$ Ray, Anthony: «Juan de Vera, azulejero de Toledo». en Boletín de la Real Academia de Bellas Artes y Ciencias de Toledo, n. ${ }^{\circ} 28$ (1992), pp. 143-151.

${ }^{25}$ Lamentablemente ninguno de estos azulejos parecen haber subsistido. Los edificios citados fueron destruidos o profundamente remodelados.

26 Artiñano: $o b$. cit. en nota 1 .

${ }^{27}$ Frothingham: ob. cit., p. 51.

${ }^{28}$ Ray: ob. cit. pág. 301.

${ }^{29}$ Cfr. Ray: ob. cit. Nota 32.
}

AEA, LXXV, 2002, 298, pp. 191 a 216 
q. los de flores que costaban a Real - cada uno . y las syntas a seis marabedis - ele tomado $\mathrm{p}^{\mathrm{a}}$ el aposento de

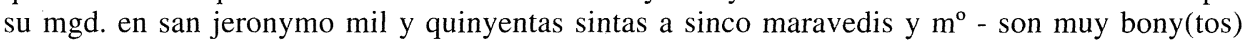

V.M. de cuenta a su mgd. y consulte si es serbydo que se lleben (roto ¿algunas?) muestras destos azulejos y sintas $\mathrm{p}^{\mathrm{a}}$ lo ber y esto (roto) más sea serbido - y con tyempo se hagan segû dyere orde (roto) (Gas) par de Vega y de lo q. faltare qye ay en la munizion q.(roto) buen presyo - y a hecho muy bonytos halbahaqueros $\mathrm{p}^{\mathrm{a}}$ el pardo a quatro Reales - que suelen costar a diez rreales - (...)

\section{Documento n. ${ }^{\circ} 2$}

24 - junio - 1569

Carta de Andrés de Ribera a Martín de Gaztelu, secretario del Consejo de su majestad, indicando los precios acordados para los azulejos..

Archivo general de Simancas. Casa y Sitios Reales, Leg. 247-1, Fol. 185

«Cuanto al maestro de azulexo yo hize sierta manera de asyento - siendo su mgd. dello serbido $\mathrm{p}^{\mathrm{a}} \mathrm{q}$. no se encaresiere alla y que - se efectuase alla como su mg mandase . si pide mas - esto - esta tratado - si menos se pudyere effetuar sera mejor y desta forma - se pudyere effetuar será mejor y desta forma se debe resolber - esta el asiento a dezisiete maravedis - todo azulejo de figuras o istoryas como quiera q. se le pidiere y a contento y de lazo o fallaxe a doce maravedis tanbyen a contento - y de la orden y manera q. se le pida - la sinta - a seys maravedis - como se le pide a contento V.M. lo comunique y si mas pidyere pare en esto y si menos será mejor - $\mathrm{p}^{\circ}$ creo no esta mal - yo le dy sus muestras para llebar alla q. su mgd. las querya ber me dixo y en esto y en todo lo demás su magd. mandara los que mas sea su servo. - nro Sor. la Illus ${ }^{\mathrm{a}}$ psona. y casa de V.M. guarde como desea de mayo y junio 24

besa las manos de Vra. md su serbydor

Andres de Ribera.

\section{Documento n. ${ }^{\circ} 3$}

15 - octubre - 1578

Informe del Gobernador de Aranjuez sobre la carta de Juan Fernández a Felipe II

Archivo General de Simancas. Casa y Sitios Reales, Leg. 247-1, Fol. 235.

«S.C.R.M.

Juan Fernandez azulejero $\mathrm{v}^{\mathbf{0}}$ de talabera dize que el a servido de diez años a esta parte a V.M. en todo lo que se le a pedido tocante a su oficio en sus Reales obras y tiene entregadas muchas muestras para aranjuez y el monesterio de san lorenço el rreal y por aberle dicho el gobernador alonso de mesa que v.m. no estaba determinado a si el chapado del dho. aranjuez sería de azulejos u de otra cosa no le dio la obra aunque para ello le embio a llamar con nombre propio y agora que biene a tomarla halla que se la quieren dar a un oficial que trabaxaba con ell en su casa de que ha rreçibido mucho agrabio y de lo que mas le pesa es que v. m. no sea bien servido ni la obra se hará como combiene por lo cual suplica a v.m. lo mande ber y probeer de manera que el no quede defraudado del trabaxo y servicio que asta aqui a echo a la rreal azienda de v. m. no sea desaprobechada porque el baxara y la hara quinientos ducados menos que la persona a quien quieren dar la obra y la hara que sea muy mas Abentajada a vista de los que lo entendieren y dara fianças a contento para cumplir lo que promete porque la obra que esta puesta en açeca costo quinze maravedys y medio y la hicyera el a quartillo porque tiene entendidos todos los secretos deste oficio y tiene todos los aparexos en su casa por donde lo puede hazer mas barato que otro y todo esto le falta a quien agora se la quieren dar la dha obra y se a de ayudar de otras personas que no lo entenderán como el y forçosamente lo que hiziere desta suerte a de ser mas caro y malo y dios es testigo que a todo esto me muebe serbir a V.M. y no otra cosa alguna»

(al reverso) «Informe el Gobernador de Araxuez de lo q. en esto passa».

AEA, LXXV, 2002, 298, pp. 191 a 216 


\section{Documento n. ${ }^{\circ} 4$}

18 - octubre - 1578, Aranjuez.

Informe de Alonso de Mesa Gobernador de Aranxuez.

Archivo General de Simancas. Casa y Sitios Reales. Leg. 247-1, Fol. 235 vto.

«S.C.R.Md.

Alonso de mesa criado de $\mathrm{V}$ Md. diçe que $\mathrm{Ju}^{\circ}$ Fernandez azulexero $\mathrm{vz}^{\circ}$ de talavera contenido en este memorial A dado mucha obra de su off ${ }^{\circ}$ para las de V.Md, de sant lorençio El Real y aranxuez y agora A benido A tratar de hacer el chapado del quarto Real de la dha. aranxuez que por orden de $\mathrm{Ju}^{\circ}$ de Herrera que lo consulto a V. Md., se le mando a Josephe de la oliva residente en toledo le hiciese conforme a çiertas muestras e disignios y traça que dio para ello y el embio a llamar $\mathrm{Al}$ dho $\mathrm{Ju}^{\circ}$ ernandez y vino aranxuez (sic) y vio las dhas muestras y disignios dadas por el dho. oliva y se trato de que ambos tomasen a su cargo la dicha obra para que se Hiçiese mejor y con mas brebedad y en efeto no se conformaron aunque se procuro porque el dho oliva dixo que tenia compañia para haçer la dicha obra con çiertos officiales de toledo y con esto el dho. ju $\mathrm{u}^{\circ}$ fernandez se fue ofreciendo que el haría tan buena obra y mejor y por menos precio que el dicho oliva y con mas brevedad y pidió una carta para juan de herrera y oliva otra y ansi escribio al dho ju de Herrera con Ambos lo que decian advirtiendo de algunos apuntamientos que se ofrecieron para que el dho ju ${ }^{\circ}$ de herrera tomase resolucion y Hiciese el asiento y concierto con los susodichos o con el que mejor pareciese lo hara y con mas comodidad porque hasta agora no esta hecho ni el precio que se ha de dar como dicho tiene y solamente lo esta en quanto al chapado que el dho. oliva hiço en el Quarto Real de açeca y con esto aguarda la orden que se embiare para que aquella se cumpla, fecho en aranxuez en diez y ocho de octubre de 1578

Fdo: Alonso de Mesa».

Alfonso Pleguezuelo

\section{UN RETRATO DE EUGENIO GARCÍA RUIZ, MINISTRO DE LA GOBERNACIÓN, POR CASADO DEL ALISAL}

Este retrato, un óleo sobre lienzo de 64,4 $\times 53,4 \mathrm{~cm}$, aparece firmado por Casado y con dedicatoria en el ángulo inferior izquierdo, de lectura incompleta pero suficiente como para haber permitido identificar al retratado, Eugenio García Ruiz, dentro de la colección a la que pertenece (Madrid).

La efigie de García Ruiz, de busto largo, ante un fondo neutro, viste traje de diario, con la chaqueta abierta luciendo sólo la leontina por encima del chaleco. Compuesto de frente, envuelto por un suave aire entre melancólico e indiferente, subrayado por su mirada miope, con la frente despejada, bigote poblado y mosca; el pintor no omite el lobanillo que el político tenía en su mejilla derecha.

Es fácil pensar que Casado del Alisal ${ }^{1}$ mantuviese una relación de amistad con Eugenio García Ruiz [Amusco (Palencia), 1818 - Madrid, 1883], de ideología republicana unitaria y agitada vida política (periodista visceral, autor polémico, protagonista de conspiraciones y exilios), quien llegó a dirigir fugazmente el Ministerio de la Gobernación en el Gobierno de Serrano $(1874)^{2}$. Una vinculación amistosa que vendría dada no sólo por la proximidad geo-

\footnotetext{
1 La vida y obra de José Casado del Alisal ha sido estudiada por Portela Sandoval, F. J.: Casado del Alisal, 1831-1886. Palencia, 1986.

${ }^{2}$ Un apunte biográfico de García Ruiz puede seguirse en El Imparcial (mayo de 1897) y El Diario Palentino (febrero de 1883 y mayo de 1897).
}

$A E A, \mathrm{LXXV}, 2002,298$, pp. 191 a 216 